\title{
1. A genetic linkage map of Pinus massoniana based on SRAP, SSR and ESTP markers
}

\author{
By WenXia Chen ${ }^{1,4)}$, Mu CaO ${ }^{1,4)}$, YuanxiU WanG ${ }^{1), 2)}$, Zhichun Zhou ${ }^{3)}$ and Li-AN Xu ${ }^{1), *}$
}

(Received $3^{\text {rd }}$ December 2012)

\begin{abstract}
Pinus massoniana (masson pine) is the most important native pine in southern China. High-density genetic maps have not been constructed for the species. In this study, a genetic linkage map with 251 markers (47 SSRs, 23 ESTPs and 181 SRAPs) was constructed using a $\mathrm{F}_{1}$ progeny mapping population derived from controlled pollination of two parents of different provenances. At LOD 7.0, a total of 17 linkage groups were constructed with twelve groups having nine or more markers and five other groups of two to four markers each. The total map length was $1,956 \mathrm{cM}$ with an average of $8.4 \mathrm{cM}$ among individual loci. The current linkage map represented $93 \%$ of the estimated genome length of $2,114 \mathrm{cM}$ for masson pine. Such linkage map are useful for future genomic studies of masson pine including comparative mapping in Pinaceae and quantitative trait loci (QTL) mapping for economically important traits.
\end{abstract}

Key words: Pinus massoniana; linkage map; SSR; SRAP; ESTP.

\section{Introduction}

Pinus massoniana Lamb. (masson pine, $\mathrm{n}=12$ ) belongs to the section Pinus of diploxylon in the genus Pinus (SAYlor, 1972; Gernandt et al., 2005). It is a native conifer that is widely distributed in the central, east, south, and southwest of China (from $21^{\circ} 41^{\prime} \mathrm{N}$ to $33^{\circ} 51^{\prime} \mathrm{N}$ in latitude and from $102^{\circ} 30^{\prime} \mathrm{W}$ to $122^{\circ} 29^{\prime} \mathrm{W}$ in longitude) with estimated distribution area about 40 million $\mathrm{km}^{2}$. It is one of the most important commercial tree species characterized by high resin production, high quality timber and an ecologically corner-stone trees in China. The tree breeding and selection of masson pine started in 1950s and its genetic improvement program was regarded as one of national priority since 1980s.

Sequence related amplified polymorphism (SRAP) marker aims at amplifying the open reading frames (ORF) with particular primer pairs. Due to its simplicity, reliability, moderate throughput, SRAP has been widely used in map construction, gene tagging, genomic

1) Key Laboratory of Forest Genetics \& Biotechnology (Nanjing Forestry University), Ministry of Education, China, 210037.

${ }^{2}$ ) College of Life Science, the Key Laboratory of Molecular Evolution and Biodiversity and the Key Laboratory of Biotic Environment and Ecological Safety in Anhui Province, Anhui Normal University, Wuhu, China, 241000.

$\left.{ }^{3}\right)$ Research Institute of Subtropical Forestry, CAF, Fuyang, Zhejiang, China, 311400.

4) These authors contributed equally to this work.

*) Corresponding author: LI-AN XU. Key Laboratory of Forest Genetics \& Biotechnology (Nanjing Forestry University), Ministry of Education, China, 210037. E-Mail address: $\underline{\text { laxu@nju.edu.cn }}$ and cDNA fingerprinting, and map-based cloning after the method was introduced (LI and QUIROs, 2001). CHEN et al. (2010) firstly used SRAP markers to construct genetic map in pine. Microsatellites or simple sequence repeat (SSR) markers are useful for the construction of genetic maps because of their abundance, high polymorphism, and co-dominant nature with distribution over the whole genome. In addition, SSR markers generally have good transferability from one species to another within the same genus (RAJORA et al., 2001; HoDGETTS et al., 2001; SHEPHERD et al., 2002), and can be used as convenient anchor points in the construction of intra-specific and inter-specific consensus maps. But in conifer species, the EST-SSR markers display comparatively better transferability than genomic SSR markers (CHAGné et al., 2004; LiEWLAKSANEEYANAWIN et al., 2004). ESTP (expressed sequence tag polymorphism) markers are generated by PCR-amplification with primers designed from cDNA sequences. The ESTP markers are same as EST-SSR markers, they are transferable between species. Analysis of ESTP markers often requires time-consuming experiments (PERRY and BOUSQUET, 1998a; BROWN et al., 2001). We use SSR and ESTP markers to construct the masson pine genetic map for future comparison between the maps in Pinaceae. The SSRs were not randomly distributed in the genome and the most part of them were in nonexpression region (HALE and FARNHAM, 2006). The SRAP markers would be added and be better for constructing the linkage group on which all markers would be randomly distributed.

Construction of genetic linkage maps is an important foundation for structural and functional genomics and is the first step towards quantitative traits loci (QTL) mapping and molecular-assisted selection (MAS) (KOLE, 2007). A number of genetic maps with high density and precision were reported in several pine species ( $P$. radiata, Devey et al., 1995; P. elliotii, BROWN et al., 2001; P. sylvestris, Komulainen et al., 2003; P. pinaster, CHAGNÉ et al., 2003; P. caribaea, SHEPHERD and Williams, 2008; P. lambertiana, JERMSTAD et al., 2011; P. taeda, EcHT et al., 2011). These maps assisted the genomic research of Pinus. Some of these maps were applied to co-locate QTLs for biological characters (NEALE and KREMER, 2011). Two genetic linkage maps for masson pine were constructed based on endosperm haploid (megagametophyte) of a single tree and RAPD markers (YIN et al., 1997; ZHENG et al., 1997; CAI and JI, 2009). The density and precision of these maps were not ideal (only 48 and 29 markers respectively linked on the two maps) and mapping populations were small (respectively including 40 and 79 individuals). In this study we 
construct a genetic linkage map of masson pine based on SRAP, SSR and ESTP makers using $120 \mathrm{~F}_{1}$ progenies whose male and female parents were from different provenances. The co-dominant markers linked on the masson pine map may serve as a bridge for comparison between masson pine genetic linkage map and maps from other Pinaceae species.

\section{Materials and methods}

\subsection{The mapping pedigree}

The female parent (PM5916) was from Zhenhai $\left(121^{\circ} 43^{\prime} \mathrm{E}, 29^{\circ} 58^{\prime} \mathrm{N}\right)$, Zhejiang province, and the male parent (PM1139) was from Cenxi (111 $\left.{ }^{\circ} 02^{\prime} \mathrm{E}, 22^{\circ} 57^{\prime} \mathrm{N}\right)$, Guangxi province. The male parent PM1139 produces more number of whorls of lateral branches, and has larger crown, lower wood basic density, and less cold tolerance than the female parent PM5916. However, PM1139 is more resistance to Bursaphelenchus xylophilus. One hundred and twenty $\mathrm{F}_{1}$ individuals were randomly selected from the controlled-pollinated cross of PM5916 × PM1139 made at Laoshan Forestry Farm $\left(119^{\circ} 03^{\prime} \mathrm{E}, 2^{\circ} 37^{\prime} \mathrm{N}\right)$ in Chun-an county, Zhejiang province.

\subsection{Molecular marker analysis \\ DNA extraction}

Total DNA was extracted from frozen young needles of the 120 progenies and the two parental trees following the protocol of DOYLE and Doyle (1987), and was purified by the method previously described (ZHANG et al., 2004). The DNA preparations were quantified by electrophoresing $2 \mu \mathrm{l}$ of each sample's DNA on $1.0 \%$ agarose gels.

\section{Primer resource}

In this study 432 pairs of SSR primers were selected, among which 30 pairs were from masson pine genome (Li et al., 2007; LIU and Ji 2009), and 402 pairs came from the genomes of other Pinaceae species. In particular, two hundred and seventy pairs SSR primers were derived from the genome of $P$. taeda, and 46, 43, 21, 10, 7, and 5 pairs from the genomes of P. strobus, Picea abies, $P$. elliotii, $P$. radiata, $P$. sylvestris, $P$. thunbergii, respectively (ELSIK and Williams, 2001; BROWN et al., 2001; TEMESGEn et al., 2001; SHEPherd et al., 2002; CHAGnÉ et al., 2003; KomUlAINEN et al., 2003; LIEWLAKSANEEYANAWIN et al., 2004; Pelgas et al., 2004). One hundred and ninety-nine pairs of ESTP primers were used in this study, among which 153 were from the genome of $P$. taeda, and 11, 10 and 25 pairs from the genomes of $P$. pinaster, $P$. elliotii and Pseudotsuga menziesii, respectively (BROwn et al., 2001; TEMESGEN et al., 2001; Chagné et al., 2003; KomUlainen et al., 2003; Pelgas et al., 2004) (details in the table 1 and appendix). For the SRAP analysis, two primers were used following the protocol of FERRIOL et al., (2003). The forward primer was 17- to 20-bp long and composed of 14-17 CGrich nucleotides and three selective bases at the 3'end. The reverse primer was $18 \mathrm{bp}$ long and composed of 15 AT-rich nucleotides with three selective bases at the 3 ' end. In our study 24 forward and 34 reverse primers were used to amplify the exonic and intronic regions, respectively.

\section{Marker analysis \\ SSR analysis}

For the SSR analysis, the PCR reaction were performed in a volume of $10 \mu$ l containing 20-50 ng of template DNA, $0.3 \mu \mathrm{M}$ of each oligonucleotide primer, $250 \mu \mathrm{M}$ of each dNTP, $0.6 \mathrm{U}$ rTaq DNA polymerase (Takara, Japan), $1 \mu$ of $10 \mathrm{X}$ reaction buffer (Tris-HCl $10 \mathrm{mmol} / \mathrm{L} \mathrm{pH} \mathrm{8.0,} \mathrm{KCl} 50 \mathrm{mmol} / \mathrm{L}$ ), $250 \mu \mathrm{M}$ of $\mathrm{MgCl}_{2}$, $0.1 \mu \mathrm{l}$ of $1 \%$ gelatin. PCR program was: $94^{\circ} \mathrm{C}$ hold for 4 min, followed by 35 cycles of denaturation at $94^{\circ} \mathrm{C}$ for $30 \mathrm{~s}$, annealing at every pair of primers temperature for $30 \mathrm{~s}$, and extension at $72^{\circ} \mathrm{C}$ for $45 \mathrm{~s}$; and then a last extension at $72^{\circ} \mathrm{C}$ for $8 \mathrm{~min}$. The SSR-PCR amplified products in $0.2 \mathrm{ml} 12$ tube strips were transferred directly from the thermocycler into the sample tray of the QIAxcel System (the resolution of the fragment analysis using QIAxcel is 2 5bp). Separation was performed using the OL700 method (sample injection voltage $8 \mathrm{KV}, 20 \mathrm{~s}$, separation voltage $3 \mathrm{KV}$ and separation time $700 \mathrm{~s}$ ) in a 12-channel gel cartridge (GCK5000) purchased from eGene Inc. (currently Qiagen, USA). The size of the alleles resolved from the subsequent separation were automatically calculated in bp and exported using the BioCalculator ${ }^{\mathrm{TM}}$ software, which provides a gel view and an electro-pherogram of the separation.

\section{SRAP analysis}

SRAP PCR reaction mixtures (total volume = 10 ?1) contained 20-50 ng of template DNA, $0.3 \mu \mathrm{M}$ of each oligonucleotide primer, $150 \mu \mathrm{M}$ of each dNTP, $0.6 \mathrm{U}$ rTaq DNA polymerase (Takara, Japan), $1 \mu \mathrm{l}$ of $10 \mathrm{X}$ reaction buffer (Tris-HCl $10 \mathrm{mmol} / \mathrm{L} \mathrm{pH} \mathrm{8.0,} \mathrm{KCl} 50 \mathrm{mmol} / \mathrm{L}$ ), $200 \mu \mathrm{M}$ of $\mathrm{MgCl}_{2}$. The thermal cycling profile was: $94^{\circ} \mathrm{C}$ hold for $5 \mathrm{~min}$, followed by 6 cycles of denaturation at $94^{\circ} \mathrm{C}$ for $1 \mathrm{~min}$, annealing at $35^{\circ} \mathrm{C}$ for $30 \mathrm{~s}$, and extension at $72^{\circ} \mathrm{C}$ for $1 \mathrm{~min}$; and 35 cycles of denaturation at $94^{\circ} \mathrm{C}$ for $1 \mathrm{~min}$, annealing at $52^{\circ} \mathrm{C}$ for $30 \mathrm{~s}$, extension at $72^{\circ} \mathrm{C}$ for $1 \mathrm{~min}$; and a final extension at $72^{\circ} \mathrm{C}$ for $7 \mathrm{~min}$. The SRAP-PCR amplified products were tested using the same method as SSR analysis.

\section{ESTP analysis}

ESTP reaction mixtures (total volume $=10 \mu \mathrm{l}$ ) contained $10 \mathrm{ng}$ DNA, $1 \mu \mathrm{l}$ of $10 \mathrm{X}$ reaction buffer of the Taq DNA polymerase, $150 \mu \mathrm{M}$ of dNTPs, $200 \mu \mathrm{M}$ of $\mathrm{MgCl}_{2}$, $0.5 \mathrm{U}$ rTaq DNA polymerase and $0.35 \mu \mathrm{M}$ of of each oligonucleotide primer. The thermal cycling program was: $94^{\circ} \mathrm{C}$ for $10 \mathrm{~min}$, followed by 35 cycles of denaturation at $94^{\circ} \mathrm{C}$ for $45 \mathrm{~s}$, annealing at every pair of primers temperature for $45 \mathrm{~s}$, and extension at $72^{\circ} \mathrm{C}$ for $60 \mathrm{~s}$, with a last extension at $72^{\circ} \mathrm{C}$ for $7 \mathrm{~min}$. Amplification products were analyzed by 'Cold SSCP' (cold single strand conformation polymorphism) and silver staining screening methods. A 1-mm-thick $8 \%$ polyacrylamide gels (29:1 acrylamide-bisacrylamide, 1X TBE buffer and $5 \%$ glycerin) was used in the buffer chamber filled with $0.5 \mathrm{X}$ TBE. A miniature peristaltic pumps equipped with a Y-tube was used to recirculate buffer chilled by passage through long coils of tubing immersed in $4{ }^{\circ} \mathrm{C}$ water 
in an ice bucket. Reaction products were mixed with an equal volume of loading dye, denatured at $98^{\circ} \mathrm{C}$ for 10 min and cooled on ice immediately to $4{ }^{\circ} \mathrm{C}$. Reactions products $(1 \mu \mathrm{l})$ were quickly loaded into different individual wells of the gel. Samples were flanked by a $50 \mathrm{bp}$ DNA ladder (from 50 to 2,000 bp) and ran at $180 \mathrm{~V}$ until the bromophenol blue dye had migrated over two thirds of the gel. After electrophoresis the gel was firstly fixed by $10 \%$ ethanol, $0.5 \%$ acetic acid for $10 \mathrm{~min}$, and then rinsed by $\mathrm{ddH}_{2} \mathrm{O}$ for 1 min three times. Next the gel was stained by $0.15 \% \mathrm{AgNO} 3$ for $10 \mathrm{~min}$ and then dipped in a solution containing $1.5 \% \mathrm{NaOH}, 0.00756 \%$ sodium borate and $1 \%$ formaldehyde after rinsed by $\mathrm{ddH}_{2} \mathrm{O}$ two times until the bands emerged clearly.

All PCR reactions were performed in a Perkin-Elmer Cetus thermocycler 2400 (Applied Biosystems, USA).

\section{Marker nomenclature}

The ESTP marker' names follow the original references. SSR marker' names follow the original references if only one polymorphic fragment was amplified, and the SSR markers were named according to the original name followed by an ordinal alphabet "a" and "b" according to the size (in base pairs) of the DNA fragments if there were two or three. For example marker PtTX3116a, PtTX3116b and PtTX3116c , the "a", "b" and "c" stand for about $180 \mathrm{bp}, 240 \mathrm{bp}$ and 300bp polymorphic DNA fragments amplified by marker PtTX3116. The SRAP markers were named according to the primer combinations used. The forward and reverse primers followed by an ordinal alphabet also according to the size of the DNA fragments scored as the SSR markers.
Segregation analysis and map construction

For each marker, a $\chi^{2}$ test $(\mathrm{P}<0.05)$ was performed to identify alleles of each parent that deviated from Mendelian segregation ratios. The deviated markers may be related with important genetic information (YIN et al, 2004), so distorted markers deviating at $\mathrm{P}<0.05$ were not excluded from linkage analysis, but indicated with the suffix “*”.

Mapping was carried out with JoinMap4.0 (STAM, 1993; VAN OOIJEN, 2006) using the regression mapping algorithm. Grouping was initially carried out from LOD 2 to 10 with a step of $0.5 \mathrm{LOD}$, but the linkage map was finally grouped at LOD thresholds of 7.0. Maps were generated using the Kosambi mapping function with recombination rates $<0.45$ and $\mathrm{LOD} \geq 0$ and a ripple with jump threshold of 5 . When complete maps for some groups could not be created due to the lack of adequate recombination (REC) and LOD information, markers within these groups were split based on linkage, and two or more groups of linkage were generated and assessed. A third round of marker addition was also conducted without re-ording the first and second generation maps. Maps were drawn with the program MapChart 2.1 (VoORRIPS, 2002).

Estimated and observed genome length and map coverage

The length of masson pine genome $(\mathrm{G})$ was estimated using the Method 4 of CHAKRAVARTI et al. (1991) after length of each group had been adjusted by the factor $(m+1) /(m-1)$, where $m$ is the number of framework

Table 1. - Molecular markers analysis for amplified, distorted, linked, and unlinked in P. massoniona.

\begin{tabular}{|c|c|c|c|c|c|c|c|c|c|c|}
\hline $\begin{array}{l}\text { Marker } \\
\text { type }\end{array}$ & $\begin{array}{l}\text { Primers' } \\
\text { Resource }\end{array}$ & $\begin{array}{l}\text { No. of } \\
\text { primers }\end{array}$ & $\begin{array}{c}\text { Amplified } \\
(\%)\end{array}$ & $\begin{array}{l}\text { polymorphic } \\
\text { primers (\%) }\end{array}$ & Markers & $\begin{array}{l}\text { Distorted } \\
\text { markers } \\
(\mathrm{P}<0.05)(\%)\end{array}$ & $\begin{array}{l}\text { Distorted } \\
\text { markers } \\
(\mathrm{P}<0.01) \quad(\%)\end{array}$ & $\begin{array}{l}\text { No. of markers } \\
\text { used to } \\
\text { mapping }\end{array}$ & $\begin{array}{l}\text { Linked } \\
\text { markers }\end{array}$ & $\begin{array}{c}\text { Unlinked } \\
\text { markers }(\%)\end{array}$ \\
\hline \multirow[t]{9}{*}{ SSR } & & 432 & $178(41.2)$ & $42(9.7)$ & 72 & $13(18.1)$ & $5(7.0)$ & 67 & 47 & $20(29.9)$ \\
\hline & P. taeda $(\mathrm{G})$ & 270 & $119(44.1)$ & $25(9.3)$ & 45 & $8(17.8)$ & $3(6.7)$ & 42 & 30 & $15(33.3)$ \\
\hline & P. taeda $(\mathrm{E})$ & 21 & $9(42.9)$ & $4(19.0)$ & 6 & $1(16.7)$ & 0 & 6 & 4 & $2(33.3)$ \\
\hline & P. radiata $(G)$ & 10 & $4(40.0)$ & $1(10.0)$ & 1 & 0 & 0 & 1 & 1 & 0 \\
\hline & Picea glauca $(\mathrm{G})$ & 43 & $9(20.9)$ & $1(2.3)$ & 2 & 0 & 0 & 2 & 2 & $1(50.0)$ \\
\hline & P. thunbergii $(\mathrm{G})$ & 5 & $3(60.0)$ & 0 & 0 & 0 & 0 & 0 & 0 & 0 \\
\hline & P. $\quad$ strobus $(\mathrm{G})$ & 46 & $12(26.1)$ & $1(2.2)$ & 2 & 0 & 0 & 2 & 1 & $1(100.0)$ \\
\hline & P. sylvestris $(\mathrm{G})$ & 7 & $4(57.1)$ & 0 & 0 & 0 & 0 & 0 & 0 & 0 \\
\hline & P. massoniana $(\mathrm{E})$ & 30 & $18(60.0)$ & $10(33.3)$ & 16 & $4(25.0)$ & $2(12.5)$ & 14 & 9 & $7(43.7)$ \\
\hline SRAP & & 640 & 251 & 183 & 671 & $99(14.7)$ & $31(4.6)$ & 640 & 181 & $459(71.7)$ \\
\hline \multirow[t]{5}{*}{ ESTP } & & 199 & $93(46.7)$ & $35(17.6)$ & 46 & $2(4.3)$ & 0 & 46 & 23 & $23(50.0)$ \\
\hline & P. taeda & 153 & $73(47.7)$ & $22(14.4)$ & 22 & $2(9.1)$ & 0 & 22 & 13 & $9(40.9)$ \\
\hline & P. pinaster & 11 & $8(72.7)$ & $7(63.6)$ & 7 & 0 & 0 & 7 & 6 & $1(14.3)$ \\
\hline & P. sylvestris & 10 & $7(70.0)$ & $4(40.0)$ & 4 & 0 & 0 & 4 & 3 & $1(25)$ \\
\hline & $\begin{array}{c}\text { Pseudotsuga } \\
\text { menziesii }\end{array}$ & 25 & $5(20.0)$ & $2(8.0)$ & 2 & 0 & 0 & 2 & 1 & $1(50.0)$ \\
\hline Total & & & & & 789 & $114(14.4)$ & $36(4.6)$ & 753 & 251 & $502(66.7)$ \\
\hline
\end{tabular}

E: EST (expressed sequence tag); G: genomic library. 


\begin{tabular}{|c|c|}
\hline $\begin{array}{l}0.0 \\
4.0 \\
16.0 \\
32.2 \\
36.3 \\
38.7 \\
41.5 \\
50.0 \\
71.5 \\
72.0 \\
74.8\end{array}$ & 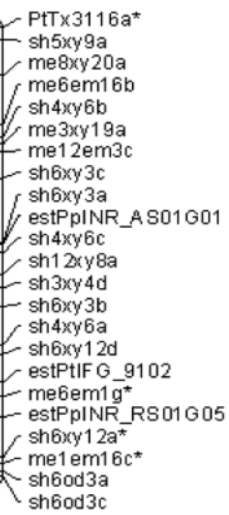 \\
\hline
\end{tabular}

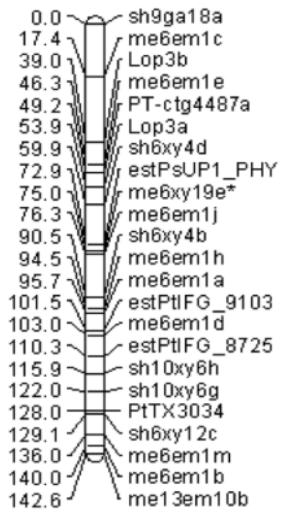

3

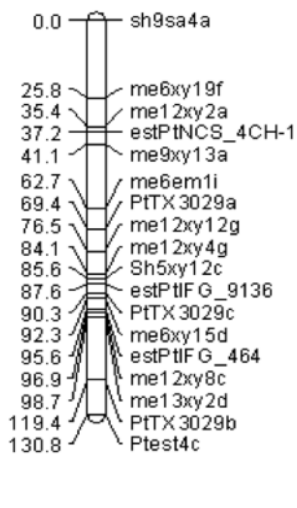

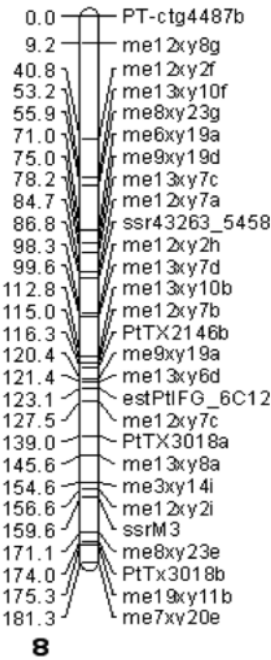

7

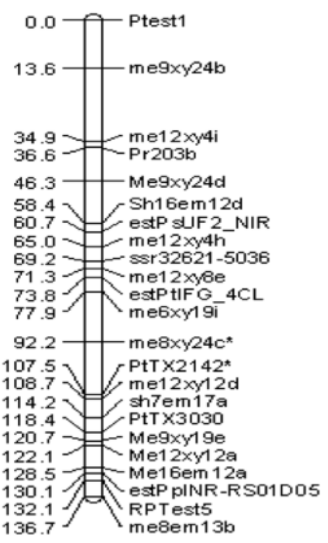

11

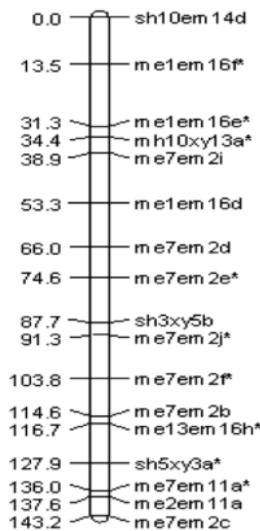

12
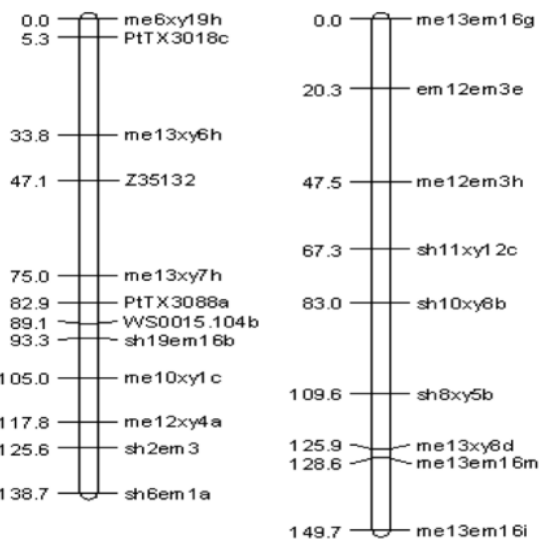

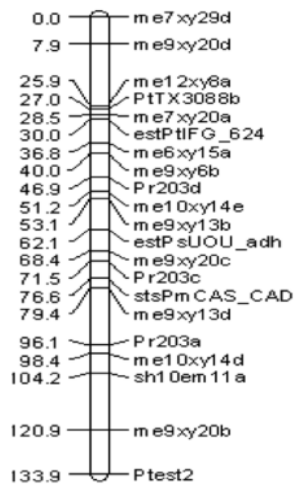

10

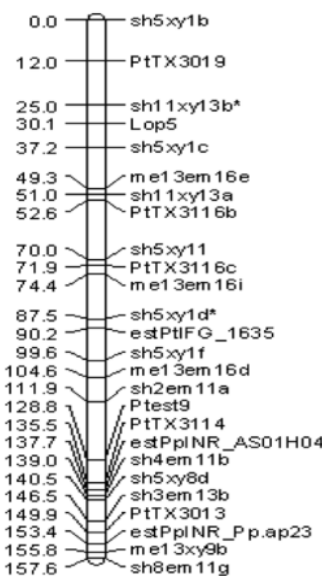

$149.7-\operatorname{me13em} 16 i$
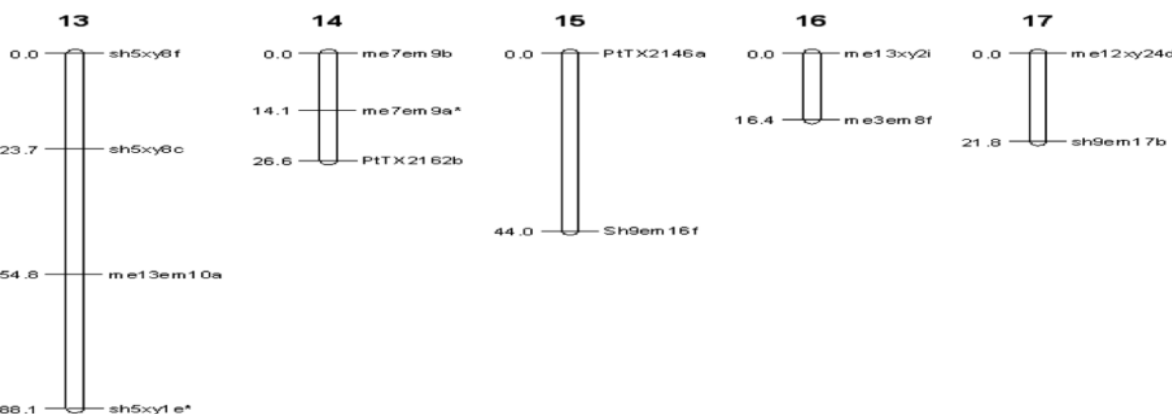

Figure 1. - Genetic linkage map of $P$. massoniona. Genetic distances in $\mathrm{cM}$ were to the left of the linkage group and marker names to the right. Distorted markers were noted with the suffix “*” . 
markers on the linkage group. The observed genome length was obtained by summing up the frame map lengths of the 13 individual linkage groups that contained more than 3 markers. The map coverage was calculated as the ratio of the observed to the estimated genome length. The full length of masson pine genome was the sum of all linkage groups (including the triplets and doublets). The full map coverage was calculated as the ratio of the full to the estimated genome length.

\section{Results}

\subsection{Molecular markers polymorphism}

Among the 432 pairs of SSR primers tested, 212 $(49.1 \%)$ did not amplify; 178 (41.2\%) failed to segregate; and $42(9.5 \%)$ generated 72 segregating loci with 1.71 segregating loci produced per pair of primers (Table 1).

Among the total of 640 SRAP primer pairs, 250 produced 5-10 clear bands each, and one produced 26 clear bands at the most. The size of amplification productions ranged from 100 to $1,000 \mathrm{bp}$, most between 150 and 800 bp. One hundred and eighty-three primer pairs $(28.6 \%$ of 640) showed polymorphism and a total of 671 polymorphic fragments were identified with a mean of 3.67 markers per primer pair (Table 1).

One hundred and ninety-nine pairs of ESTP primers were screened by SSCP technology, and 93 pairs $(46.7 \%)$ could produce PCR productions. Thirty-five (17.6\%) showed polymorphism and a total of 46 polymorphic fragments were identified with 1.31 markers per pair on average (Table 1).

The analysis of genetic origin the polymorphic loci could shed lights whether the selected mapping popula- tion was adequate for the construction of genetic map. If the marker segregations are from one parent only, the reliability and application of the map would be reduced. In this study, among 72 SSR and 46 ESTP polymorphic loci, $51(43.2 \%)$ were maternally informative [ab $\times$ aa, $1: 1] ; 54(45.8 \%)$ were paternally [aa $\times$ ab, 1:1]; 13 $(11.0 \%)$ were fully informative loci [ab $\times a b, 1: 2: 1$, $\mathrm{ab} \times \mathrm{cd}$ and $\mathrm{ab} \times \mathrm{ac}, 1: 1: 1: 1]$. Of $671 \mathrm{SRAP}$ polymorphic loci $328(48.9 \%)$ were maternally informative, 330 $(49.2 \%)$ paternally, and $13(1.9 \%)$ fully informative loci. The segregating ratio of the marker loci from the maternal parent in the whole population was similar to the ratio from the paternal parent. Thererfor, both parents supplied nearly similar genetic information to their filial generation and the selected mapping population was proper to be used for construction of the masson pine genetic map.

\subsection{Segregation distortion}

Chi-squared analysis was performed to test the null hypothesis of $1: 1(\mathrm{df}=1)$ segregation of partial informative markers and the null hypothesis of $1: 2: 1(\mathrm{df}=2)$ and 1:1:1:1 $(\mathrm{df}=3)$ segregation of full informative markers. 114 markers (14.4\% of 789) showed distorted segregation $(\mathrm{P}<0.05)$, including $36(4.6 \%)$ serious distorted segregation $(\mathrm{P}<0.01)$. The numbers and the percentage of distorted markers for each marker type were shown in Table 1. The percentage of the distorted markers (18.1\%) for SSR was a bit higher than SRAP (14.7\%). Of 114 distorted markers used to construct the map, 28 were linked on the map. Twenty-five of the 28 linked markers were SRAPs. The markers that deviated from expected ratio were labeled by the symbol “*” after their marker names (Figure 1).

Table 2. - Main characteristics of markers and genetic distance per linkage group in P. massoniona.

\begin{tabular}{rcccccccc}
\hline $\begin{array}{c}\text { Linkage } \\
\text { group }\end{array}$ & $\begin{array}{c}\text { No. of } \\
\text { markers }\end{array}$ & $\begin{array}{c}\text { No. of } \\
\text { SSRs }\end{array}$ & $\begin{array}{c}\text { No. of } \\
\text { ESTPs }\end{array}$ & $\begin{array}{c}\text { No. of of } \\
\text { SRAPs }\end{array}$ & $\begin{array}{c}\text { Length } \\
\text { (cM) }\end{array}$ & $\begin{array}{c}\text { Maximum of } \\
\text { distance between } \\
\text { two markers (cM) }\end{array}$ & $\begin{array}{c}\text { Mimimus of } \\
\text { distance between } \\
\text { two markers (cM) }\end{array}$ & $\begin{array}{c}\text { Average distance } \\
\text { between two } \\
\text { markers (cM) }\end{array}$ \\
\hline 1 & 22 & 1 & 3 & 18 & 149.0 & 21.5 & 1.4 & 7.10 \\
2 & 23 & 4 & 3 & 16 & 142.6 & 21.6 & 1.1 & 6.48 \\
3 & 18 & 4 & 3 & 11 & 130.8 & 25.8 & 1.5 & 7.69 \\
4 & 28 & 6 & 1 & 21 & 181.3 & 31.6 & 1.0 & 6.71 \\
5 & 18 & 5 & 0 & 13 & 154.9 & 23.6 & 0.3 & 9.11 \\
6 & 21 & 3 & 4 & 14 & 141.1 & 26.1 & 3.2 & 7.06 \\
7 & 23 & 6 & 3 & 14 & 136.7 & 21.3 & 1.2 & 6.21 \\
8 & 17 & 0 & 0 & 17 & 143.2 & 17.8 & 1.6 & 8.95 \\
9 & 21 & 5 & 3 & 13 & 133.9 & 18.0 & 1.1 & 6.70 \\
10 & 26 & 7 & 3 & 16 & 157.6 & 17.4 & 1.2 & 6.30 \\
11 & 12 & 4 & 0 & 8 & 138.7 & 28.5 & 4.2 & 12.61 \\
12 & 9 & 0 & 0 & 9 & 149.7 & 27.2 & 2.7 & 18.71 \\
13 & 4 & 0 & 0 & 4 & 88.1 & 33.3 & 23.7 & 29.37 \\
14 & 3 & 1 & 0 & 2 & 26.6 & 14.1 & 12.5 & 13.30 \\
15 & 2 & 1 & 0 & 2 & 44 & 44 & 44 & 44.00 \\
16 & 2 & 0 & 0 & 2 & 16.4 & 16.4 & 16.4 & 16.40 \\
17 & 2 & 0 & 0 & 2 & 21.8 & 21.8 & 21.8 & 21.80 \\
Total & 251 & 47 & 23 & 181 & 1956.4 & & & 8.4 \\
\hline
\end{tabular}




\subsection{Mapping}

A total of 753 markers were used to calculated average pairwise LOD and REC data. Using LOD thresholds of 7.0, the final map contained 251 markers (47 SSRs, 181 SRAPs and 23 ESTPs) that were mapped on 12 linkage groups and one quadruplet, one triplet and three doublets. Twelve linkage groups have markers ranged from 9 to 28 . The total map distance with the 17 linkage groups was $1,956.4 \mathrm{cM}$ with an average length of linkage group of $114.5 \mathrm{cM}$. The length of the linkage groups ranged from $16.4 \mathrm{cM}$ to $181.3 \mathrm{cM}$. The distance between two adjacent markers on the linkage group varied from $0.3 \mathrm{cM}$ to $44.0 \mathrm{cM}$ with an average distance of $8.4 \mathrm{cM}$ between any two adjacent markers (Figure 1 and Table 2).

\subsection{Expected and observed genome length and map coverage}

The estimated length of the masson pine genome was 2,113.6 cM based on the method of CHAKRAVARTI et al. (1991). In our study the frame map covered $87.4 \%$ of the estimated genome length of masson pine, and the full map covered more than $92 \%$ of the estimated genome length (Figure 1 and Table 2).

\section{Discussions}

\subsection{Markers analysis}

SRAP marker integrating the advantages of RAPD and AFLP markers has been recognized as a new and useful molecular marker system. Our study is the first to use SRAP markers for linkage mapping of masson pine. Of the 671 polymorphic SRAP markers identified by 183 primer combinations (3.67 on average), $27.0 \%$ (181) were mapped into linkage groups, which was lower than the $54.2 \%(96 / 177)$ found to be linked to the $P$. koraiensis map constructed at LOD threshold of 4.0 (CHEN et al., 2010). In our study, with LOD lowered to $5.0,249(37.1 \%)$ polymorphic SRAP markers were linked on 21 the masson pine linkage groups. Of 21 linkage groups there were 5 doublets full of SRAP markers. When LOD threshold of 7.0 was used, 192 polymorphic SRAP markers were mapped into 17 linkage groups with 3 doublets full of doublets. The reason of the low percentage of this marker linked to the map might be owe to the large genome of Pinus (NEALE and WiLliaMs, 1991) and the characteristics of the polymorphic loci amplified by the SRAP primer pairs in our mapping population. The polymorphic loci from the different open reading frames $(\mathrm{ORF})$ in a large genome might be far apart from each other and other type loci, and could not be linked together at LOD threshold of 7.0.

The transferability of SSR and ESTP primers might be closely related with the genetic (taxonomic) relationship among different species. In this study, 432 pairs of SSR primers and 199 pairs of ESTP primers were from genomes of 9 tree species in Pinaceae (see the part of 'Primer resource' and table 1), and the most of them (SSR: $62.5 \%$; ESTP: $76.9 \%$ ) were from the genome of P. taeda. In the genus Pinus the genetic relationship between masson pine and $P$. thunbergii, $P$. sylvestris and
$P$. pinaster were closer than that between masson pine and $P$. taeda, $P$. radiata, $P$. elliotii and $P$. strobus (GERNANDT et al., 2005). Picea abies and Pseudotsuga menziesii respectively belong to Picea and Pseudotsuga in Pinaceae. The EST-SSR markers were still better transferability than genomic SSR as described in CHAGNÉ et al. (2004) and LIEWLAKSANEEYANAWIN et al. (2004). The total proportion of the transferable SSR primers used in the genome of masson pine was $41.2 \%$ (Table 1), and that of the transferable EST-SSR primers was 53\%. The EST-SSR primers developed from EST database (http://www.ncbi.nlm.nih.gov/dbEST/index.html) (LI et al., 2007; LIU and Ji, 2009) were identified to be transferable in the genome of masson pine with a proportion of $60 \%$ in our mapping population, and 10 of them were polymorphic. The SSR primers from $P$. thunbergii and $P$. sylvestris had good transferability, and near to $60 \%$ of them could amplify in masson pine, but unfortunately the primers from these species were too few to detect any polymorphism. Over $40 \%$ of the SSR primers from $P$. taeda and $P$. radiata were transferable, and only $26 \%$ and $21 \%$ of that from $P$. strobus and P. abies. Most of the transferable SSR primers tested in our mapping population yielded single amplification patterns and $42(9.7 \%)$ were polymorphic. About $80 \%$ of polymorphic primers were complex multilocus amplification patterns, probably due to the high proportion of repetitive DNA that is characteristic of Pinus genomes in which microsatellite sequences can be embedded (SCHMIDT et al., 2000; ELSIK and Williams, 2001; ACHERÉ et al., 2004).

The proportion of the transferable ESTP primers used in our study was $46.7 \%$ (Table 1) with respectively $50.6 \%$ of that from $P$. taeda, P. pinaster, and P. sylvestris and only $20 \%$ from Pseudotsuga menziesii. Forty-eight percent of ESTP primers from the genome of $P$. taeda were transferable in masson pine, lower than that in the genomes of $P$. pinaster $(72.7 \%)$ and $P$. sylvestris $(70.0 \%)$ and higher than that in the genome of Pseudotsuga menziesii $(20.0 \%)$. But the proportion of polymorphic ESTP primers was only $14 \%$ in the genome of masson pine and lower than that in three species mentioned above (CHAGné et al., 2003; KomUlainen et al., 2003; KRUTOVsKY et al., 2004). Different sources of primers used, for example, the closeness of source species to masson pine, could have impacted the detection of polymorphism of SSR and ESTP in masson pine, and the structure of mapping populations also affects the detection.

The SSR and ESTP markers mapped on masson pine will provide an important tool for comparative mapping in Pinaceae. The syntenic relationship had been observed through the studies of comparative genome mapping between the genetic maps of $P$. radiata, $P$. elliotii, $P$. sylvestris, $P$. pinaster, $P$. caribaea, $P$. lambertiana, Pseudotsuga menziesii and species in Picea and the genetic map of $P$. taeda). There were RFLP, SSR, ESTP and $\operatorname{COS}$ (conserved orthologous sequence) markers used in the comparative mapping (DEVEY et al., 1995; Brown et al., 2001; KomUlaINEN et al., 2003; CHAGNÉ et al., 2003; KRUTOVsKY et al., 2004; PELGAS et al., 2006; SHEPHERD and WiLliAMs, 2008; JERMSTAD et al., 2011). Thirty-eight homeologous-like markers were observed 
through the primary comparison between our masson pine map and 7 genetic maps in Pinaceae using the SSR and ESTP markers (results not showed). However, due to low polymorphism, the co-dominant markers linked on the map of masson pine were not available to compare effectively with genetic maps in Pinaceae. Hence, using the large genome database of Pinus, the more co-dominant makers, especially based on functional genomic information (ECHT et al., 2011), are developed or found to improve the density and precision of the linkage map of masson pine.

\subsection{Genetic linkage map}

In this study, we report the first integrated genetic linkage map containing SRAP, SSR and ESTP markers for masson pine based on a large mapping population (the $\mathrm{F}_{1}$ individuals). The previous masson pine maps were constructed based on megagametophytes only of single tree (YIN et al., 1997; ZHENG et al., 1997; CAI and JI, 2009). Single-tree genetic maps based on segregation of markers in haploid megagametophytes of maternal trees did not take into account the segregation or recombination of markers in the paternal trees. Therefore, single-tree linkage maps were not as informative as genetic maps developed from diploid segregating pedigreed populations. Genetic mapping using megagametophyte in previous studies has limitation that further QTL study using the same population is not possible (KANG et al., 2011). The $\mathrm{F}_{1}$ masson pine mapping population in this study could be further used for QTL mapping for growth and adaptation traits.

\subsection{Genome length and map coverage}

The masson pine genome length estimated in our study was $2,113.6 \mathrm{cM}$. The number of the chromosomes in masson pine's haploid is 12 . If the previous 12 linkage groups (9-12 markers on them) were regarded as the masson pine frame map, the length estimated was $1,966.8 \mathrm{cM}$. This was consistent with the genome length of about 2,000 cM (K) reported for Pinus (GERBER and Rodolphe, 1994; Plomion et al., 1995; Echt and NelSON, 1999; REMINGTON et al., 1999; Costa et al., 2000; YIN et al., 2003; SHEPHERD et al., 2003). The estimated length in different species could be diverse owing to difference in the mapping populations used, variation in recombination rates of the parents, the number and types of markers, and the choice of mapping softwares and functions. For example, Kosambi's mapping algorithm leads to shorter map distances than Haldane's, and Mapmaker software leads to larger group length than Joinmap (LIU, 1998; REMINGTON et al., 1999). KIM et al. (2005) estimated the genome length of $P$. densiflo$r a$ was 2,662 cM using Mapmaker software at LOD threshold of 4.0 and the recombination rate of 0.25 . Recently ECHT et al. (2011) reported the estimation of the genome length of the $P$. taeda was $1,515 \mathrm{cM}$ using Joinmap software and the same estimating methods as that we used in this study (12 linkage groups were regarded as the frame map of $P$. taeda). CAI and JI (2009) estimated the genome length of masson pine was $2,541.21 \mathrm{cM}$ which was $20.2 \%$ longer than ours. Their estimation was based on FsLinkageMap (http://fgbio.
njfu.edu.cn/tong/FsLinkageMap/FsLinkageMap.htm) at LOD threshold of 2.0 and 3.0 and the default recombination rate of 0.5 .

\subsection{Conclusion and prospect}

A mapping population using controlled cross of two parental trees from different provenances was generated for masson pine linkage map. A total of 120 trees from the mapping population were used for genotyping and linkage analysis using three kinds of markers (SSR, ESTP and SRAP markers). Joinmap software was used to construct a new linkage map of 251 markers (47 SSRs, 23 ESTPs and 181 SRAPs) in masson pine. Our new map used more markers and larger population than previous map for masson pine and will be a valuable tool for identifying and localizing QTLs for an important biomass and cold and insect resistance traits. Also highly saturated maps could be of great value for comparative mapping.

\section{Acknowledgments}

This work was supported by the National High Technology Research and Development Program of China (863 Program: 2006AA100109) and „A Project Funded by the Priority Academic Program Development of Jiangsu Higher Education Institutions (RAPD)“.

\section{References}

Acheré, V., P. Faivre-Rampant, S. Jeandroz, G. Besnard, T. Markussen, A. Aragones, M. Fladung, E. RitTer and J. M. FAVRE (2004): A full saturated linkage map of Picea abies including AFLP, SSR, ESTP, 5S rDNA and morphological markers. Theoretical and Applied Genetics 108: 1602-1613. doi: 10.1007/s00122-004-1587-y

Brown, G. R., E. E. Kadel, D. L. Bassoni, K. L. Kiehne, B. Temesgen, J. P. Van Buittenen, M. M. Sewell, K. A. Marshall and D. B. Neale (2001): Anchored reference loci in Loblolly pine (Pinus taeda L.) for integrating pine genomics. Genetics 159: 799-809.

CAI J. and K. JI (2009): Diversity of SSR Markers and strategy of genetic linkage map making with masson's pine egagametophytes (in Chinese). Molecular Plant Breeding 7: 934-940. doi: 10.3969/mpb.007.000934

Chagné, D., G. Brown, C. Lalanne, D. Madur, D. Pot, D. Neale and C. Plomion (2003): Comparative genome and QTL mapping between maritime and loblolly pines. Molecular Breeding 12: 185-195.

Chakravarti, A., L. K. Lasher and J. E. Reefer (1991): A maximum likelihood for estimating genome length using genetic linkage data. Genetics 128: 175-182.

Chen, M., F. Feng, X. Sui, M. Li, D. Zhao and S. Han (2010): Construction of a framework map for Pinus koraiensis Sieb. et Zucc. using SRAP, SSR and ISSR markers. Trees 24: 685-693. doi: 10.1007/s00468-0100438-5

Costa, P., D. Pot, C. Dubos, J. M. Frigerio, C. Pionneau, C. Bodenes, E. Bertocchi, M. T. Cervera, D. L. Remington and C. Plomion (2000): A genetic map of maritime pine based on AFLP, RAPD and protein markers. Theoretical and Applied Genetics 100: 39-48. doi: 10.1007/s001220050006

Devey, M. E., A. Delfino-Mix, B. B. Kinloch JR and D. B. NEALE (1995): Random amplified polymorphic DNA 
markers tightly linked to a gene for resistance to white pine blister rust in sugar pine. Proceedings of the National Academy of Sciences 92: 2066-2070.

Doyle, J. J. and J. L. Doyle (1987) A rapid DNA isolation procedure for small quantities of fresh leaf tissue. Phytochemistry Bullettin 19: 11-15.

ECHT, C. S. and C. D. Nelson (1997): Linkage mapping and genome length in eastern white pine (Pinus strobus L.). Theoretical and Applied Genetics 94: 1031-1037. doi: 10.1007/s001220050511

Echt, C. S., S. SAHA, K. V. KRutovsky, K. Wimalanathan, J. E. ERPelding, C. Liang and C. D. Nelson (2011): An annotated genetic map of loblolly pine based on microsatellite and cDNA markers. BMC Genetics 12: 17. [Online journal]. Available at: http://www.biomedcentral.com/1471-2156/12/17

Elsik, C. G. and C. G. Williams (2001): Families of clustered microsatellites in a conifer genome. Molecular Genetic Genomics 265: 535-542. doi: $10.1007 / \mathrm{s} 004380100443$

Ferriol, M., B. Pico and F. Nuez (2003): Genetic diversity of a germplasm collection of Cucurbita pepo using SRAP and AFLP markers. Theoretical and Applied Genetics 107: 271-282. doi:10.1007/s00122-003-1242-z

GERBER, S. and F. Rodolphe (1994): An estimation of the genome length of maritime pine (Pinus pinaster Ait.). Theoretical and Applied Genetics 88: 289-292. doi: 10.1007/BF00223634

Gernandt, D. S., G. Lopez, S. O. Garcia and A. Liston (2005): Phylogeny and classification of Pinus. Taxon 54: $29-42$.

Hale, A. L and M. W. FARnham (2006): Use of PCR-based markers for differentiating elite Broccoli inbreds. Journal of the American Society for Horticultural Science 131(3): 418-423.

Hodgetts, R. B., M. A. Aleksiuk, A. Brown, C. Clarke, E. MacDonald, S. Nadeem and D. Khasa (2001): Development of microsatellite markers for white spruce (Picea glauca) and related species. Theoretical and Applied Genetics 102: 1252-1258. doi: 10.1007/s00122001-0546-0

Jermstad, K. D., A. J. Eckert, J. L. Wegrzyn, A. DelfinoMix, D. A. Davis, D. C. Burton and D. B. Neale (2010): Comparative mapping in Pinus: sugar pine (Pinus lambertiana Dougl.) and loblolly pine (Pinus taeda L.). Tree Genetics \& Genomes 7: 457-468. doi:10.1007/s11295010-0347-1

KANG, B.Y., J. E. MAJOR and O. P. RAJORA (2011): A highdensity genetic linkage map of a black spruce (Picea mariana) - red spruce (Picea rubens) interspecific hybrid. Genome 54: 128-143. doi:10.1139/G10-099

KIM, Y., H. CHOI and B.Y. KANG (2005): An AFLP-based linkage map of Japanese red pine (Pinus densiflora) using haploid DNA samples of megagametophytes from a single maternal tree. Molecular Cells. 20: 201-209.

Kole, C. (2007): Genome mapping and molecular breeding in plants, volume 7, forest trees. Springer, Berlin

Komulainen, P., G. R. Brown, M. MikKonen, A. Karhu, M. R. Garía-Gil, D. O’Malley, B. Lee, D. B. Neale and O. Savolainen (2003): Comparing EST based genetic maps between Pinus sylvestris and Pinus taeda. Theoretical and Applied Genetics 107: 667-678. doi: 10.1007/s00122-003-1312-2

Krutovsky, K.V., M., Troggio, G. R. Brown, K. D. Jermstad and D. B. NeAle (2004): Comparative mapping in the Pinaceae. Genetics 168: 447-461. doi: 10.1534/genetics.104.028381
LI, D., K. JI and J. GoNG (2007): Microsatellite Enrichment by Magnetic Beads in Pinus massoniana (in Chinese). Molecular Plant Breeding 5: 141-144.

LI, G. and C. F. Quiros (2001): Sequence-related amplified polymorphism (SARP) a new marker system based on a simple PCR reaction: its application to mapping and gene tagging in Brassica. Theoretical and Applied Genetics 103: 455-461. doi:10.1007/s001220100570

Liewlaksaneeyanawin, C., C. E. Ritland, Y. A. El-KassaBY and K. RITLAND (2004): Single-copy, species-transferable microsatellite markers developed from loblolly pine ESTs. Theoretical and Applied Genetics 109: 361-369. doi: $10.1007 / \mathrm{s} 00122-004-1635-7$

LiU, B. H. (1998): Statistical genomics: linkage mapping and QTL analysis. CRC Press, Boca Raton, Fla.

LIU, G. and K. JI (2009): Designing Pinus massoniana SSR Primers from Pinus EST sequences (in Chinese). Molecular Plant Breeding 7: 833-838. doi:10.3969/ mpb.007.000833

Neale, D. B. and A. Kremer (2011): Forest tree genomics: growing resources and applications. Nature Reviews Genetics 12: 111-122. doi:10.1038/nrg2931

Neale, D. B. and C. G. Williams (1991): Restriction fragment length polymorphism mapping in conifers and application to forest genetics and improvement. Canadian Journal of Forest Research, 21(5): 545-554. doi:10.1139/x91-076

Pelgas, B., S. Beauseigle, V. Acheré, S. Jeandroz, J. Bousquet and N. IsABel (2006): Comparative genome mapping among Picea glauca, $P$. mariana $\mathrm{x}$ P. rubens and $P$. abies, and correspondence with other Pinaceae. Theoretical and Applied Genetics 113: 1371-1393. doi: 10.1007/s00122-006-0354-7

Pelgas, B., N. Isabel and J. Bousquet (2004): Efficient screening for expressed sequence tag polymorphisms (ESTPs). Molecular Breeding 13: 263-279. doi: 10.1023/B:MOLB.0000022528.01656.c8

PerRY, D. J. and J. Bousquet (1998): Sequence-taggedsite (STS) markers of arbitrary genes: the utility of black spruce-derived STS primers in other conifers. Theoretical and Applied Genetics 97: 735-743. doi:10.1007/s001220050950

Plomion, C., N. Bahuman, C. E. Durel and D. M. O'Malley (1995): Genomic mapping in maritime pine (Pinus pinaster) using RAPD and protein markers. Heredity 74: 661-668.

RAJORA, O. P., M. H. RAHMAN, S. DAYANANDAN and A. MosSELER (2001): Isolation, characterization, inheritance and linkage of microsatellite DNA markers in white spruce (Picea glauca) and their usefulness in other spruce species. Molecular and General Genetics 264: 871-882. doi: 10.1007/s004380000377

Remington, D. L., R. W. Whetten, B. H. LiU and D. M. O'MALLEY (1999): Construction of an AFLP genetic map with nearly complete genome coverage in Pinus taeda. Theoretical and Applied Genetics 98: 1279-1292. doi: $10.1007 / \mathrm{s} 001220051194$

SAYLOR, L. C. (1972): Karyotype analysis of the genus Pinus-subgenus Pinus. Silvae Genetica 21: 155-163.

Schmidt, A., R. L. Doudrick, J. S. Heslop-HarRison and T. SCHMIDT (2000): The contribution of short repeats of low sequence complexity to large conifer genomes. Theoretical and Applied Genetics 101: 7-14. doi: 10.1007/s001220051442

ShePherD, M. and C. G. Williams (2008): Comparative mapping among subsection Australes (genus Pinus, family Pinaceae). Genome 51: 320-331. doi: 10.1007/s00122-002-1185-9 